\title{
A ausência do Congresso do Mundo Português no ensaio História do Brasil, de Afrânio Peixoto
}

The Absence of the Portuguese World Congress in the Essay, History of Brazil by Afranio Peixoto

Cleber Santos VIEIRA ${ }^{\bullet}$

Resumo: Este artigo analisa o ensaio História do Brasil, publicado por Afrânio Peixoto em 1940. Entende-se que, em sua estrutura interna, o livro comporta nuances dos conflitos entre o autor e o Estado Novo brasileiro (1937-1945) e também em relação ao teor autoritário, com o qual a ditadura portuguesa, comandada por Antônio Salazar, modelou o Congresso do Mundo Português (1940). Muito embora tenha colaborado para a organização do evento, na última hora, por ordem expressa do governo brasileiro, Afrânio Peixoto foi impedido de participar das comemorações. Nesse sentido, busca-se demonstrar que uma das razões capaz de explicar sua ausência foi o patriotismo luso-brasileiro praticado por Afrânio, o qual o colocou em rota de colisão com as representações oficiais preparadas para aquela efeméride.

Palavras-chave: História do Livro; Patriotismo; Intelectuais e Poder; República; Congresso LusoBrasileiro.

Abstract: This article analyzes the essay, History of Brazil, published by Afranio Peixoto in 1940. It is well understood that in the content of this book there are a number of nuances concerning the conflicts between the author and the Brazilian New State (1937-1945), and also between him and the authoritative style, with which the Portuguese dictatorship, led by Antonio Salazar, modeled the Portuguese World Congress of 1940. Although he had contributed to the event's organization, at the last minute by express order of the Brazilian government, Afranio Peixoto was barred from attending the commemoration. To this effect, one of the reasons explaining Afranio's absence is sought to be shown to be his Luso-Brazilian patriotism, which put him on a collision course with the official representations prepared for that occasion.

Keywords: History of the Book; Patriotism; Intellectuals and power; Republic; Luso-Brazilian Congress.

No prefácio ao livro História do Brasil, Afrânio Peixoto explicitou o porquê da publicação: pretendeu homenagear duas nações, Portugal e Brasil, tendo por fio condutor a história da América Portuguesa. Nas palavras do autor:

na hora de um duplo centenário, o da fundação e o da restauração da nacionalidade, o que um brasileiro patriota, de melhor, pode oferecer, à Pátria de sua Pátria, é a história mútua, essa história da América Portuguesa, história do Brasil [...] (PEIXOTO,1940, p.VI).

Prefácios, por definição, são todos os discursos produzidos a propósito do texto que se segue (GENETTE, 2001, p.137). São instâncias de comunicação entre o autor e leitor e compõem o conjunto de estratégias discursivas que preparam e mobilizam o leitor para a recepção do texto

\footnotetext{
- Professor Doutor - Programa de Pós-Graduação em Educação - USF - Univ. São Francisco - Rua Alexandre Rodrigues Barbosa, 45, CEP: 13251-900, Itatiba, São Paulo, Brasil. E-mail: clebersvieira@yahoo.com.br
} 
(CHARTIER, 1997, p.70). Prefácios, enfim, são protocolos de leitura que se posicionam entre as coisas do mundo e o mundo dos livros, isto é, dispositivos situados entre o arcabouço sócio-cultural que recobre a produção do impresso e a existência do impresso, incluindo aí ação autoral. A leitura atenta desses objetos revela, muitas vezes, as marcas históricas de determinado livro. Nesse sentido, as reticências do prefácio à História do Brasil estão longe de significar mero recurso gramatical. Ao contrário, parecem convidar o leitor a uma incursão pelo universo do não-dito, a pensar, certamente, sobre a ausência do Congresso do Mundo Português no prefácio e no livro História do Brasil, de Afrânio Peixoto.

O livro foi publicado em 1940 por uma das mais tradicionais editoras portuguesas, a Livraria Lello \& Irmão, Editores. Nesse mesmo ano, conforme vem demonstrando os trabalhos da historiadora Lúcia Maria Paschoal Guimarães (GUIMARÃES, 2007 e GUIMARÃES, 2006), o governo de Antônio Salazar realizava o Congresso do Mundo Português, projetado para reforçar, com hinos, símbolos e festejos, as lides autoritária e nacionalista do Estado Novo Lusitano. No mesmo prefácio, Afrânio Peixoto reverencia a Academia Portuguesa da História e à Academia Brasileira de Letras qualificando-as como a razão de existência do Ensaio: "a Academia Brasileira, fazendo-me seu, obrigou-me a escritor; a Academia Portuguesa da História, elegendo, inesperada e surpreendentemente, obriga a cumprir comigo, e é disto culpada.” (PEIXOTO, 1940, p.VI)

Esse também foi o ano do Congresso, cuja realização foi possível graças, em grande parte, ao empenho de uma ampla rede de sociabilidade formada por intelectuais brasileiros e portugueses. Afrânio Peixoto incluía-se entre eles, tendo, inclusive, participado ativamente da comissão organizadora do evento como designado por decreto oficial do presidente Getúlio Vargas. Realizado em Lisboa, o evento pretendia celebrar os dois marcos históricos das origens de Portugal, a fundação (1340) e restauração do Reino (1640). Nessa história, espaço especial seria destinado aos expositores brasileiros. Todavia, o evento transformou-se em mero mecanismo de propaganda política, tonificando o nacionalismo autoritário praticado pelo Estado Novo instalado nas Repúblicas de um lado e de outro do oceano atlântico. E, muito embora tenha participado ativamente da organização do evento na condição de membro do Instituto Histórico e Geográfico Brasileiro (IHGB), Afrânio Peixoto não participou do evento.

A ausência, é claro, não passou despercebida. Na inauguração do evento, Júlio Dantas, membro da Academia Portuguesa da História (APH) e presidente da comissão organizadora, ao saudar a delegação brasileira, leu um lacônico telegrama que lhe fora enviado por Afrânio Peixoto: "Não posso ir a Portugal; não posso estar no Santuário; mas, meu amigo, - até logo!” (DANTAS, 1940, p.266).

Uma das justificativas mais difundidas para a ausência dava conta de que a Guerra impediu a partida do navio que levaria a delegação brasileira. A versão foi incessantemente reproduzida. Em 
data não muito distante, 1989, ao discursar durante as homenagens prestadas pela APH ao sesquicentenário do IHGB, o cel. Carlos Bessa, secretário geral da entidade portuguesa, reportou a ausência de membros do Instituto no Congresso com as seguintes palavras:

Devido à guerra, a Embaixada brasileira veio a ser reduzida por à ultima hora muito dos seus componentes se verem impedidos de embarcar. Acabou por ficar constituída apenas pelos membros que já se encontravam em Lisboa: o comandante Eugênio de Castro, Gustavo Barroso e Oswaldo Orico. Dos brasileiros recebeu o Congresso quarenta comunicações e memórias e, entre elas, as de diversos membros do Instituto (BESSA, 1989, p.413).

Mais recentemente, essa posição tem sido revista. Em artigo recente, Lúcia Maria Paschoal Guimarães (GUIMARÃES, 2007, p.49-66), demonstrou que o enigma da mensagem telegrafada por Afrânio, bem como a resignação de Júlio Dantas, resultaram das interdições promovidas por representantes da diplomacia das ditaduras dos dois países envolvidos: O Estado Novo de Salazar e o de Getúlio Vargas. Daí as lamentações de Júlio Dantas serem compreendidas também como a manifestação resignada da comunidade de intelectuais formada por escritores brasileiros e portugueses envolvidos em diversas instâncias culturais desde o início do século XX. Impedido de participar das comemorações, por ordem expressa do Ministro das Relações Exteriores, inclusive pela intervenção direta de Osvaldo Aranha, a publicação de História do Brasil sugere, então, uma interpretação sobre a intervenção literária de Afrânio nas Comemorações de 1940.

Nesse sentido, as reticências do prefácio à História do Brasil parecem tão enigmáticas quanto o telegrama lido na abertura do Congresso de História Luso-Brasileiro e nos leva a qualificá-las enquanto expressão de um dos mais característicos estilos do autor: "a frase curta, a malícia do pensamento encoberta nas reticências, que obrigam o leitor a completar o que não foi dito" (VIANA FILHO, 1949, p.11-12).

Seguindo as pistas deixadas por Lúcia Guimarães, este artigo investiga outras nuances históricas conexas ao impedimento de Afrânio Peixoto. Busca-se demonstrar que a publicação do livro História do Brasil foi expressão dos conflitos e, por isso, portador de um discurso lusobrasileiro dissidente em relação às comemorações oficiais preparado para aquela efeméride. Partese do pressuposto de que o ato de telegrafar o "mas, meu amigo, até logo!" remete a um momento de parada, de reflexão em que Afrânio Peixoto sugeriu aos leitores - e Júlio Dantas facultou aos ouvintes - certa atenção para os sentimentos e interpretações patrióticas luso-brasileiras impedidas de se manifestar no Congresso do Mundo Português.

A História do Brasil foi publicada em 1940 quando o Estado Novo apresentava-se como traço comum entre os regimes políticos adotados no Brasil e em Portugal. O Estado Novo, personificado na figura de Antônio de Oliveira Salazar, que instalado em 1926, completava 14 anos (TORGAL, 
2001, p.391-415), enquanto o de Getúlio Dornelles Vargas, inaugurado em 1937, fechava o triênio. Não obstante as especificidades históricas de cada país, pode-se dizer que não só pelo nome assemelharam-se o Estado Novo de Portugal e o do Brasil. Ambos emergem sob o discurso de fortes críticas à democracia liberal. Para além da democracia política, Salazar e Vargas reivindicaram também a social para o primeiro plano das ações do Estado, cujos resultados dirigiram-se à construção de um tipo de integração social ao corpo político pela via do corporativismo. São similares ainda na fortíssima campanha anticomunista apoiada pelo catolicismo conservador. Mas a identidade política comum aos dois países revelava-se, sobretudo, nos percalços das frágeis e recentes repúblicas. Quando golpeada, a primeira república lusitana atingia parcos dezesseis anos, marcados por fortes crises desde sua instalação em 1910. No Brasil, o golpe de 1937 colocou as comemorações da quarta década republicana tupiniquim sob os auspícios da ditadura.

Mas, as reflexões que guiam este texto não pretendem agrupar em único argumento os conflitos entre Afrânio Peixoto, Getúlio e o Estado Novo. Esse aspecto foi demasiadamente explorado por diferentes autores e enfoques. Tristão de Athayde, no prefácio à biografia do autor de Maria Bonita preparada por Leonídio Ribeiro, já em 1950 rememorava Afrânio como alguém que desafiou governos e ditaduras posicionando-se ao lado de outras personalidades que se empenharam pelas liberdades democráticas:

Foi o que sucedeu, por exemplo, com Sobral Pinto, a quem Afrânio colocava como homem a quem mais admirava, entre os que durante a ditadura do Estado Novo, soube conservava-se sempre como sentinela avançado das liberdades essenciais da pessoa humana (ATHAYDE, 1950, p.XVII-XVIII).

Também Luis Viana Filho, asseverando acerca da instalação de ditaduras na América no contexto de Guerra, afirmou:

Afrânio Peixoto, entretanto, não se conformou, e menos aceitou a ditadura indígena, a que deram o nome de Estado Novo. E enquanto essa existiu, permaneceu refugiado nas suas cátedras, na composição dos seus livros, ensinando com o exemplo aquilo que então era permitido ensinar com a palavra (VIANA FILHO, 1963, p.06).

$\mathrm{Na}$ galeria dos escritores que ressaltaram as refregas entre Afrânio e a ditadura varguista é cabível, ainda, citar o acadêmico Alberto Venâncio Filho, que em discurso proferido na sessão de homenagem à memória de Afrânio pela Academia Brasileira de Letras (ABL), registrou que o intelectual foi um dos principais opositores da entrada de Getúlio Vargas nos quadros da academia:

Depois da eleição de Vargas, em 1941, Afrânio deixou de comparecer com habitualidade às sessões, frequentando a Biblioteca e o Arquivo. Se por acaso 
comparecia ao Plenário, tinha cuidado de tirar da carteira um recorte de cartolina branca onde se achava escrita a palavra em caracteres gregos: Silêncio (VENÂNCIO FILHO, 2007, p.33).

$\mathrm{Na}$ esfera educacional os atritos entre Afrânio Peixoto e a ditadura foi relatada por Eliane Marta Teixeira Lopes. Vem à tona o círculo de amizade de Afrânio Peixoto com personagens como Fernando de Azevedo, que praticamente articulou a assinatura do autor no Manifesto dos pioneiros da Educação. Nutria amizade com Anisio Teixeira, em solidariedade ao qual renunciou ao cargo de Reitor da Universidade do Distrito Federal (UDF), após aquele ter sido demitido da Secretaria de Educação, acusado de ligações com o comunismo (LOPES, 2008, p.660-661).

As áreas de atrito aqui relatadas não eximem Peixoto de ter participado em algumas ocasiões de comissões do estado varguista, nem tampouco de ter transitado pelos circuitos culturais lusobrasileiros, criados a partir das aproximações entre Vargas e Salazar. Bastaria para isso lembrar que em razão de seus estudos sobre medicina legal, colaborou no projeto de reforma e modernização policial efetivado na década de 1930. Conforme demonstrou um dos biógrafos de Afrânio Peixoto: “durante o governo provisório de Getúlio Vargas, a Chefia de Polícia foi entregue ao médico e político gaúcho Batista Luzardo. Para sanear, reformar e modernizar a polícia, constituiu uma comissão de que fazia parte Afrânio Peixoto" (MOTA, 1994).

\section{II}

Bem antes do Estado Novo, o discurso histórico luso-brasileiro de Afrânio Peixoto provocava polêmica. Em publicações anteriores, Afrânio já demonstrara desarmonia em relação ao ufanismo republicano praticado por outros autores contemporâneos. É o caso, por exemplo, do manual de educação cívica Minha terra minha gente, livro destinado às classes primárias. No momento da publicação (1919), Peixoto transitava por diversos pontos da rede de sociabilidade formada pelas instâncias política, intelectual e educacional que se entrecruzavam em torno da produção e difusão do livro na primeira república. Além de membro da ABL e do IHGB, exerceu importantes funções políticas junto ao poder público: Diretor de Instrução Pública do Distrito Federal em 1916, deputado federal pela Bahia em 1924, reeleito em 1930 e reitor da Universidade do Distrito Federal. Analisemos, por um momento, a história da proclamação da república através das suas representações neste livro escolar.

O livro possui uma forma distinta de narrar a história nacional, cujas raízes remetem às origens portuguesas que operam como coordenadas de todos os acontecimentos seguintes. Por esta lógica, a Proclamação da República, por exemplo, foi o resultado da evolução natural do processo civilizatório iniciado em 1500. Chegada a hora da proclamação, “a Monarchia partiu, quase sem 
saudades, também sem protestos, a 15 de novembro de 1889" (PEIXOTO, 1929, p.170). O caminho para a República foi pavimentado pelas ações da Monarquia Portuguesa para manter a unidade territorial e proteger os povos formadores da nacionalidade. Esta interpretação deslocou acontecimentos internos à America Portuguesa os quais, ao longo da história, questionaram a situação colonial - Conjuração Mineira de 1789 e a Revolução Pernambucana em 1817, por exemplo - para uma esfera secundária, quiçá para o âmbito do acidental. Foram apresentados como tentativas baldadas da tendência republicana do Brasil, sufocadas por um episódio de importância maior: a transferência da corte portuguesa em função da invasão francesa em Portugal.

Por esse caminho, o reinado de D. João VI na América portuguesa (1808-1821) é visto como o ponto de intersecção entre o desejo de liberdade por parte da colônia e as reformas promovidas pelo monarca, as quais "nos preparavam comtudo para a emancipação, mas sob o aprendizado monárchico" (PEIXOTO, 1929, p.174). Esta passagem explicita a emancipação política como ato pedagógico da corte portuguesa arrolada no decorrer do Brasil-Metrópole. Em decorrência, a passividade do povo brasileiro em relação à preponderância lusitana nos negócios econômicos, políticos e culturais do Império foi retratada da seguinte forma:

O Brasil libertou-se do governo português; continua, comtudo, a supportar, agora sem mais impaciências, a ascendência dos lusitanos no seu comércio, indústria, imprensa e até nas letras, à qual nos submetemos com uma passividade que não seria tamanha se viesse apenas da gratidão do que fizeram por nós, pelo que lhe devemos, de tradição e exemplos (PEIXOTO, 1929, p.142-143).

Analisando o jogo político do reinado de Pedro II, Afrânio Peixoto dirá que o governo honesto e liberal do imperador destoava das repúblicas caudilhescas e oligárquicas do restante da América do Sul. Para ele, o descontentamento ante a monarquia não passa de ambição. A agitação de setores sociais no final do século XIX em torno do movimento republicano, por sua vez, não teria alterado o curso natural da evolução política, mas apenas reproduziram a "scena de ingratidão e rebeldia que depusera o primeiro imperador."

$\mathrm{Na}$ análise de Afrânio Peixoto, porém, o povo desempenhou um papel mais insignificante do que os bestializados da famosa frase atribuída ao propagandista Aristides Lobo. República e povo representam fenômenos plenamente dissociados tendo sido obsoletos os republicanos empenhados em atenuar as distâncias:

Disse Aristides Lobo, um d'estes, que o povo brasileiro assistira a isto, "bestificado"; é um engano, assistira indifferente, indifferente á sorte da Monarchia. Quanto á República, que devia vir naturalmente, chegou, por um caminho comprido, adiada por D. João VI, por D. Pedro I, por D. Pedro II, mas chegou finalmente, como devia chegar ou teria chegado sem elles (PEIXOTO, 1929, p.178-179). 
Nesse sentido, Minha terra, minha gente é um testemunho engajado revelador de um dos gabaritos de inteligibilidade histórica sobre o nascimento da república ${ }^{1}$. Em Afrânio Peixoto, o regime republicano não concretizou sonhos e esperanças. Tampouco a República foi responsável por todos os benefícios que apenas foram realizados sob sua vigência, pois as linhas evolutivas foram dadas pela monarquia. Diria, então, que, em Minha terra, minha gente, a República é representada como a conclusão política da monarquia portuguesa, conclusão talvez precipitada, mas uma conclusão política verdadeira.

É bem verdade, que o fluxo desse autor e desse livro pela rede de sociabilidade luso-brasileira, não implicou em consenso, nem imunizou Afrânio dos seus críticos. João Kopke, em artigo publicado na Revista do Brasil em 1919 atacou de forma bastante contundente o manual de Peixoto "parecia especialmente condenável a maneira pessimista, pouco patriótica e desentusiasmada de apresentar ao público infantil a história do país, o que em nada contribuía para a formação do caráter cívico dos alunos” (LUCA, 1999, p.94-95). Para esse autor, o livro era completamente inadequado ao público-leitor infantil, pois, escrito em linguagem demasiadamente abstrata e inundado de conceitos e fatos que mais confundiriam do que educariam as crianças brasileiras. A crítica de Kopke expôs as rivalidades que permeavam as relações entre intelectuais e, ao mesmo tempo, a preocupação em se definir a melhor forma de fazer do livro instrumento eficaz na escolarização do público infantil.

Em todo caso, a segunda edição de Minha terra, minha gente, confirma a relevância de Afrânio na rede de intercâmbio formada pela intelectualidade luso-brasileira. O posfácio registrou as manifestações publicadas por escritores na imprensa portuguesa e brasileira pelas quais a importância do livro era reconhecida. O então diretor de instrução pública de Portugal, João de Barros, em nota publicada no jornal o Paiz em 26 de março de 1916, afirmou “o patriotismo mais são e mais esclarecido anima as suas páginas e conquista o leitor: em todo ele passa e vibra um grande amor pelo velho Portugal" (PEIXOTO, 1929, p.236) ${ }^{2}$. Em outra ocasião, em carta publicada a 30 de março de 1916 no Jornal do Commercio, afirmou: “o Ministério de Instrução Pública acaba de abrir aqui um concurso para um livro como o seu - de educação cívica e patriótica. Só desejo, para bem das crianças portuguezas, que os autores dos futuros volumes tomem por modelo o Minha Terra e Minha gente" (PEIXOTO, 1929, p.236).

Gil Vidal, jornalista, deputado e professor de direito publicou texto na edição de 20 de março de 1916 do Correio da Manhã nos seguintes termos:

a sua comprehensão de como se deve fazer a educação cívica, embora incontestável, será contestada. Suppõe que há de ser feita com o conhecimento da causa, as razões do patriotismo, buscadas nas origens e nas tradições, continuadas na história da formação nacional, alcançado o período em que vivemos, no qual 
após a emancipação política procuramos a emancipação econômica, bem mais difícil de conseguir (PEIXOTO,1929, p.237-238).

O escritor Mário Brant rasgou elogios ao colega da Academia Brasileira de letras:

as linhas geraes da nossa história são apresentadas sem disfarces e sem exageros. Aos vultos mais notáveis são rendidas homenagens proporcionaes á sua benemerencia. A Monarchia é apresentada com imparcialidade nos benefícios que nos deu e nos defeitos que minaram o throno. A República é exhibida com a sua superioridade theorica e suas decepções práticas. A parte final está recheiada de verdades com que o autor teve a coragem de chocar as susceptilidades do paiz, embalada pela literatura patriótica (PEIXOTO,1929, p.239).

Para afirmar a proximidade, laços de amizades e literários que Afrânio mantinha com os círculos letrados de Portugal, bastariam assinalar a inserção de Agostinho de Campos. A edição de 5 de abril de 1916 do Jornal do Comércio levou ao público brasileiro jocoso artigo que, entre outras coisas, o ex-ministro e reformador da instrução pública em Portugal afirmava:

e aqueles que se conhecem o Brasil pelo que delle lêem nos nossos jornaes sem sinceridade, ou pelo que delle lhes contam re-immigrados sem philosophia, encontrarão ali um Brasil novo, quase diria desconhecido. Há muito mais que descobrir no Brasil em 1926 do que havia em 1500 [...] (PEIXOTO, 1929, p.248).

Do lado da intelectualidade brasileira, os elogios partiram do escritor João do Rio, cujo texto, publicado no jornal O Paiz em 26 de março de 1916, foi inteiramente reproduzido por Afrânio. "uma geração, a nossa, estabeleceu o princípio de que patriotismo é querer a sua pátria igual ás maiores, sem copia-las. Para isso, é preciso conhecer as origens, sentir o sangue, comprehender os erros para amar conscientemente melhorando" (PEIXOTO, 1929, p.241). Conforme destacou Lúcia Maria Paschoal Guimarães (GUIMARÃES, 2006, p.02), nesse período Afrânio Peixoto atuou como colaborador da revista Atlântica, publicada em Lisboa entre 1910 e 1915 dirigida por João de Barros e Paulo Barreto. De modo que não era de se estranhar a presença do autor de "A alma encantadora das ruas", reconhecendo as especificidades luso-brasileiras no discurso histórico de Minha terra, minha gente. De acordo com João do Rio, o texto de Peixoto demonstrou originalidade em relação ao conjunto de representações nacionais que passaram a compor a produção didática do período, justamente por ressaltar os traços lusitanos presentes na cultura brasileira e debatendo a até então propalada máxima de que o Brasil era um país de futuro incerto, uma eterna carta sem endereço.

Para Mônica Pimenta Velloso, Afrânio Peixoto foi "um dos pioneiros na crítica à tese europeia dos trópicos insalubres. Ao argumentar que a raça e o clima não constituíam empecilho ao desenvolvimento, apontava uma visão positiva da nacionalidade" (VELLOSO, 2003, p.354). Nesse 
sentido, segundo a autora, os argumentos de Paulo Barreto podem ser sintetizados da seguinte maneira.

sugeria que era necessário respeitar quem colocou a carta no correio. O que significava amar o passado, reforçando-se os vínculos com as tradições lusas. Em seguida, dizia que era necessário saber o que cotinha essa carta (conhecer o Brasil). Finalmente, alertava para a necessidade de endereçá-la corretamente para que viesse a cumprir o destino grandioso que lhe estava reservado (VELLOSO, 2003, p.356).

\section{III}

O patriotismo luso-brasileiro posto em História do Brasil retomou as perspectivas lançadas em Minha terra, minha gente. Afrânio, todavia, as coloca nas características da história dos dois países naquela conjuntura. No prefácio, Afrânio escreveu que na inexistência de uma história do Brasil, lacuna ainda a ser preenchida pela historiografia, apoiou-se em um conjunto de ensaios antigos e recentes estudos para produzir o enredo histórico da América Portuguesa. Dentre os ensaios, destacou Vanrhagen, Capistrano de Abreu, Rodolfo Garcia, Alfredo de Taunay, Roberto Simonsen, Pedro Calmon, Serafim Leite. No desdobrar dos capítulos aparecem outros autores, cujas obras incrementam tópicos específicos: é o caso de Rocha Pita, Heytor Lira, Duarte Leite, J. Lúcio de Azevedo. A este vasto repertório de ensaístas e historiadores, acrescentem-se as crônicas, cartas, diários e outros gêneros discursivos de importante cunho testemunhal transformados em fontes documentais pela historiografia. Neste caso, figuram os testemunhos de Padre Vieira, as narrativas de Pero Vaz e Pedro Gândavo.

A frase "Suceda o que suceder, o Brasil será sempre uma herança de Portugal”, extraída do parágrafo inicial do capítulo que encerra a coletânea História do Brasil de Roberth Southey (SOUTHEY, 1965), posiciona-se no formato de epígrafe e epílogo de História do Brasil de Afrânio Peixoto (PEIXOTO, 1940). As insígnias que emolduram o livro indicam, em primeiro lugar, um processo de apropriação da tese de que independentemente dos acontecimentos o Brasil seria uma herança de Portugal. Será preciso, antes de tudo, penetrar na estrutura interna do "texto primeiro" para entender o contexto original da frase. A interpretação de Roberth Sothey decorre da análise das mudanças políticas transcorridas na ordem mundial no fim do século XVIII, notadamente a revolução Francesa (1789) e a Independência dos Estados Unidos da América (1776). Quanto aos impactos das revoluções burguesas, Southey é categórico em afirmar a imunidade brasileira, preferindo assinalar a prosperidade vivenciada pelo Brasil: "Durante os primeiros anos da guerra revolucionária, achando-se toda a Europa em armas, continuou o Brasil não perturbado em estado de rapidamente crescente prosperidade. Também melhorou o espírito do governo" (SOUTHEY, 
1965, p.208-209). Muito mais importante do que ressaltar a leitura e o registro da época histórica desenhados por Southey, é trazer à luz os tópicos do parágrafo que inspiraram a epígrafe e o epílogo do livro de Peixoto. É preciso, então, revelar os temas sobre os quais Afrânio Peixoto silencia, mas que complementam a frase e conotam o sentido da herança lusitana no Brasil. Lembremos os excertos extraídos por Peixoto:

Nunca jamais houve nação que em proporção dos seus meios tanto fizesse como a portuguesa. Pequeno como é Portugal, um dos mais diminutos reinos da Europa, e longe de ser bem povoado, apoderou-se por bom direito de ocupação da parte bela do mundo novo, e suceda o que suceder, sempre o Brasil há de ser herança de um povo lusitano (SOUTHEY, 1965, p.223).

O trecho citado inaugura o capítulo nomeado "Progressos do Brasil no Correr do Século XVIII e Seu Estado ao Tempo de Passar-se Para Ali a Sede do Governo", o qual encerra-se com a seguinte passagem:

\begin{abstract}
Estende-se o Brasil em comprimento por trinta e quatro graus de latitude, e na parte mais ancha a largura lhe iguala o comprimento. Ao transferir-se de Lisboa para aqui a sede do governo, muito divergiam entre si, segundo a latitude e a altura das províncias e outras circunstâncias locais, os costumes e a condição dos moradores, mas por toda a parte era português o povo, português na linguagem, português nos sentimentos e animosidades provinciais não as havia. Apesar de muitas causas que o tinham contrariado, muito grande era o progresso geral feito no século antecedente (SOUTHEY, 1965, p.223).
\end{abstract}

Unidade territorial, povo miscigenado, prosperidade econômica e instituições políticas advindas da Europa civilizada. Este é o quadro pintado no texto primeiro. O expressivo relato de Southey inicia-se pelo norte da colônia em um detalhado mergulho na história da província do Pará; segue os limites da região e províncias do nordeste; alcança Matogrosso, Goiás e Minas Gerais para chegar a São Paulo, Rio de Janeiro e, finalmente, nas províncias do Sul. Neste percurso, o autor desenha a presença das populações, das atividades econômicas, das características de cada região em termos de recursos naturais, conflitos, aliás, muitos conflitos, entre os fazendeiros e índios. Eis a herança de Portugal. Em Southey, a frase 'suceda o que suceder' soa como prognóstico de alguém que vivia em uma época explosiva pautada por profundas transformações no mundo europeu, articulada à revolução industrial, às guerras napoleônicas e à transferência da corte portuguesa ao Brasil em 1808. Este último evento, diz Southey, viria servir de blindagem ao progresso brasileiro contra os ventos da revolução.

É importante lembrar que o historiador inglês "concebia o processo histórico, até a própria colonização, como etapa do aperfeiçoamento da razão no processo evolutivo e cíclico da moral 
humana" (DIAS, 1974, p.235). Afrânio Peixoto, apropriando-se do aparato analítico formulado por Southey, interpreta a empresa colonizadora portuguesa na América após a chegada da Corte lusitana ao Rio de Janeiro, em 1808, até o limiar da primeira república. Ou seja, O que era apenas um quadro histórico hipotético em Southey, torna-se fato social com Afrânio Peixoto. O que é prognóstico em Southey, reaparece em Afrânio Peixoto como etapa do processo histórico, desdobramento de uma estratégia política. O governo de D. João VI é descrito como a época da maioridade da América portuguesa significando a transformação da colônia em nação. Pensamento este que pode ser sintetizado na frase, "achou uma colônia: deixou uma nação [...] é, assim, Portugal que nos prepara a autonomia" (PEIXOTO,1940, p.163).

Aqui, fez a maioridade da colônia em nação, dotando-a de toda a complexa máquina administrativa de governo e de todos os órgãos culturais, da civilização. Tomou posse do país e com as leis idôneas ao Brasil, aqui e não lá, permitiu a fermentação apressada da vida, que faz suprir o tempo. Foi uma experiência de governo autônomo a que nos deu. Na realidade, a nossa independência de 1808. Quase tudo o que temos foi o que nos concedeu o seu governo, liberal, tolerante, adaptada ao grande território que lhe proporcionou a fortuna (PEIXOTO,1940, p.163).

Desse modo, se o 'suceda o que suceder' remete às incertezas de Southey em relação ao futuro da América Portuguesa, lança para este mesmo futuro o discurso sobre a fundação da nação que, independentemente dos rumos históricos, carregaria os elementos constitutivos da civilização portuguesa. Afrânio Peixoto transforma hipótese em verdade histórica na medida em que, primeiro, interpreta a emigração da corte portuguesa, em 1808, como estratégia política. E em segundo lugar, crava, retrospectivamente, a ideia de que a autonomia do Brasil circunscreve, igualmente, uma estratégia política portuguesa. Apoiando-se em um documento amplamente divulgado entre os historiadores, Afrânio fixa a ação política de Portugal no incerto futuro traçado por Southey. Ou seja, explica e fundamenta a independência citando a conhecida recomendação de D. João VI ao filho Pedro II:

O Brasil brevemente se separará de Portugal; se assim for, põe a coroa sobre tua cabeça, antes que algum aventureiro lance mão dela". Com isto, esse conselho e este príncipe, permitiu que esse imenso país continuasse unido como não aconteceu ao domínio espanhol repartido em vinte e tantas nações das três Américas, norte, centro e sul (PEIXOTO,1940, p.163).

Opera-se, então, uma viragem linguística na qual 'suceda o que suceder' de Southey, torna-se o 'tal pai, tal filho'. Recurso, aliás, que percorre toda a narrativa da História do Brasil de Afrânio Peixoto, até mesmo nos momentos nos quais o autor nega determinadas proposições. Pode-se entrever esse aspecto do discurso nas andanças de Peixoto pelo escopo historiográfico acerca dos 
primeiros anos da colonização e do suposto esquecimento do Brasil. Neste tópico, Peixoto expõe um confronto aberto entre os historiadores, particularmente em relação à ideia de "Brasil esquecido". Curiosamente, o autor subtrai o postulado de Roberth Southey presente no prefácio do Tomo I, relativo aos primeiros anos de colonização, onde o inglês afirmava que o Brasil "descoberto por acaso, e ao acaso abandonado por muito tempo, tem sido com a indústria individual e cometimentos particulares, que tem crescido este império, tão vasto como já é, e tão poderoso como um dia virar a ser" (SOUTHEY, 1965, p.21).

Afrânio Peixoto preferiu afirmar verdades negando a assertiva do Brasil abandonado, ou Brasil esquecido, a partir do debate com João Ribeiro. Após um longo balanço das realizações portuguesas na colônia embasadas nos dados da história econômica emprestados de Roberto Simonsen, sentencia que: "É profundamente injusto e doloroso ouvir, e ler, de um ingrato nativismo, - que vive, ainda hoje, como a fazer a independência do Brasil - ouvir, e ler, que o Brasil foi esquecido." (PEIXOTO, 1940, p.74). Para a seguir completar:

Portugal, comparado a qualquer das nações colonizadoras de ontem e de hoje, foi benemérito, julgado em si, teve a abnegação que só tem, na linguagem humana, um epíteto: foi materno [...] como essas criaturas divinas que morrem, ou ficam perpetuamente enfermas, esvaídas de fadiga e fraqueza, por terem a glória de haver criado um filho muito grande [...] Filho às vezes ingrato: também é da natureza (PEIXOTO, 1940, p.75).

A representação da América Portuguesa como uma grande família permeará todo o restante da narrativa. O 'suceda o que suceder' de Robert Southey, discurso fundador da forma de se pensar as relações entre Portugal e Brasil, ganha, em Afrânio Peixoto, contornos metafóricos tipicamente naturalistas referindo-se às relações de uma família, precisamente das relações entre pais e filhos. A rede de suportes que sustentam a viragem linguística abrange vários ramos discursivos, inclusive os textos literários. O caso de José de Alencar é exemplar. Por um lado, em matéria dos elementos constitutivos do patriotismo, o romance Iracema é descrito como o antiexemplo, visto que o mito do bom selvagem, para Afrânio, não passa de falsificação romântica. Neste caso, o estudioso investe pesados argumentos contra o que ele chamou de falsificação patriótica do selvagem brasileiro produzida por José Alencar e outros expoentes do Romantismo do séculos XVIII e XIX. No ato de recusa ao retorno valorativo à natureza e ao primitivismo preconizado por Alencar, Peixoto afirmará o Romantismo como corrente fundadora do pensamento em relação aos índios que "depois de os exterminarmos, vem-nos, não a penitência, mas a falsificação romântica pretendidamente patriótica [...]" (PEIXOTO, 1940, p.41). 
Paradoxalmente, o mesmo autor e o mesmo romance são apropriados para afirmar verdades sobre a história do Brasil. Assim, no mundo das metáforas, Iracema torna-se exemplar no sentido de fundamentar a penosa responsabilidade da mãe-pátria na construção do Brasil:

Esse Brasil foi uma criação contínua de Portugal. No romance simbólico de Alencar, o filho de Iracema é "filho da dor' [...] o Brasil esquece, ás vezes, o que custou: o pai andava pelos expedientes da miséria, mas ao filho nada faltou para se defender, crescer prosperar" (PEIXOTO, 1940, p.101).

Por fim, é importante ressaltar a forma pela qual a noção de patriotismo evolui no texto de Peixoto. A primeira referência aparece ainda na análise das primeiras décadas do século XVI, antes mesmo da instalação do governo Geral, do sistema de capitanias hereditárias e sesmarias. Na interpretação de Peixoto, a primeira manifestação do patriotismo ocorre da percepção produzida pela exuberância da terra. Fundamenta o patriotismo da terra nos textos de Caminha, Nóbrega e Anchieta. É o mito do paraíso terrestre, em que se plantando tudo dá, assim resumido "este primeiro louvor na boca e na pena dos visitantes, e até dos habitantes, jamais cessou, até agora. O patriotismo brasileiro é sempre da terra: a gente ainda não conta.” (PEIXOTO, 1940, p.35).

Quando, pela primeira vez, a 'gente' brasileira passa a figurar na plenitude das características construídas e difundidas pela história e ciências sociais, está articulada às guerras de expulsão dos holandeses no nordeste brasileiro. As narrativas das invasões Holandesas no final do século XII é o momento em que se opera a constituição da nação em termos de escrita da História. Segundo Jaime Pinsky, ela compõe parte essencial da História Geral do Brasil publicado por Adolf Varnhagen em 1850 (PINSKY, 2002, p.14). Temos, então, a reafirmação da ideia da existência de uma unidade étnica, entre índios, negros e portugueses na defesa do território nacional: "Nela operaram feitos de valor o índio Felipe Camarão, o Negro Henrique Dias, o Branco Vidal Negreiros, simbólicos heróis das três raças do país que já defendiam, com os portugueses o Brasil” (PEIXOTO, 1940, p.112).

E continua

Nos neo-portugueses estão o esforço conjugado dos portugueses do Brasil, dos Brasileiros já possuidores de "patriotismo nacional" com a colaboração dos índios e dos negros (PEIXOTO, 1940, p.116-117).

Após enunciar o apego à terra, a ocupação e a defesa do território nacional pelas três raças, Peixoto avança para o campo das letras no sentido de identificar os autores que primeiramente manifestaram o nacionalismo. Neste aspecto, o nacionalismo foi engendrado como expressão dos sintomas da rebeldia colonial, extensão dos tempos de falência de autoridade decorrentes do liberalismo e do iluminismo europeus. Dentre outras questões, o mundo moderno, interpreta Peixoto, reduziu a importância dos jesuítas. No Brasil, a prova seria a expulsão desse corpo 
religioso pela administração do Marquês de Pombal. Assim, dos atritos entre Coroa portuguesa e jesuítas emergiu a palavra do Padre Antônio Vieira simbolizando, nos Sermões, a insatisfação manifesta nas províncias do Maranhão, Pernambuco, Bahia e Minas Gerais contra a exploração econômica. "Tudo o que se tirar do Brasil, com o Brasil se há-de gastar!" Vieira é precursor do "nacionalismo" brasileiro, antes da hora. Portugal tudo nos deu, até isso" (PEIXOTO,1940, p.149).

Como entender essa afirmação ambígua na qual o elogio à emergência do nacionalismo brasileiro figura ao lado de uma interpretação precipitada deste nacionalismo?

Por um lado, a ideia fundamenta-se na conhecida versão de que a missão dos jesuítas era de integrar os indígenas ao mundo civilizado através do rigoroso processo de aculturação e educação. Fortalece a análise descrevendo a importância dos jesuítas, cristãos católicos por definição, partindo, paradoxalmente, das considerações de um historiador protestante:

Os jesuítas eram os padres Manuel da Nóbrega, superior, Azpicoeta Navarro, Antônio Pires e Leonardo Nunes, os irmãos Diogo Jácome e Vicente Rodrigues. Tão grande parte, diz um autor independente, por estrangeiro e prostestante, Roberth Southey, - tomaram os jesuítas na história da América do Sul, que estes primeiros nomes se tornam dignos de memória (PEIXOTO, 1940, p.80).

Por outro lado, a precipitação do nacionalismo decorre da visão organicista do mundo social que entendia ‘as revoluções como pecados da evolução' (PEIXOTO, 1940, p.298). O Brasil ainda não estava preparado para a autonomia, visto que, no processo evolutivo, a maioridade da nação somente seria conquistada com a instalação da corte portuguesa em 1808:

o século findava, quase madura a colônia, para a maioridade ou liberdade, começada com a dos Estados Unidos em 1776 e que iria alastrar-se pelas três Américas, norte, centro e sul. O Brasil tomaria outro rumo, graças a Portugal. Mas a maioridade seria um facto, pelo exemplo, um imperativo. Já são mais de 3.000.000 os habitantes do Brasil. A neutralidade que tomou Portugal na Guerra entre Inglaterra e suas Colônias americanas, deu favor à agricultura e à exportação do Brasil, concorrentes ocupados em se debaterem, e nós com os nossos negócios. A maioridade se apressa pela prosperidade (PEIXOTO, 1940, p.150-151).

A última referência direta ao patriotismo enunciado por Afrânio concatena-se ao ofício do historiador, como também da sua visão de história. Ele se reporta ao contexto das desilusões republicanas quando opera um balanço dos tempos monárquicos comparando-o com as primeiras décadas do regime instalado em 1889. De acordo com Peixoto: "É triste dizê-lo, mas história não é apologia e o patriotismo não exclue as verdades amargas, que podem ser tônicas." (PEIXOTO, 1940, p.186). 
Quando da morte de Afrânio Peixoto um dos historiadores homenageados no prefácio de História do Brasil, Serafim Leite, autor da História da companhia de Jesus, foi um dos poucos autores a comentar a obra:

assumindo para frontispício da sua "História do Brasil" a famosa frase de Southey, historiador inglês: - "suceda o que suceder, o Brasil será sempre uma herança de Portugal- Afrânio retratou-se nela de corpo inteiro, e deu a explicação profunda da sua permanente amizade à terra e gente portuguesa (RIBEIRO, 1949, p.339).

A leitura intensiva do livro comentado por Serafim Leite aponta para a relativização desta assertiva. Historiadores da Literatura brasileira e biógrafos de Afrânio Peixoto já enfatizaram que o uso de ironia e enigmas sempre ocupou lugar central em suas narrativas. A começar por $A$ Esfinge, título que definitivamente o lançou no mundo literário. Este traço acompanhou toda a trajetória e, conforme afirmou Luis Vianna Filho:

No fim da vida, como se não tivesse mais tempo ou palavras para nos transmitir tudo quando aprendera, observara, e meditara, Afrânio Peixoto confiou muitas coisas às reticências de que estão cheias as suas crônicas. Era o Saci a divertir-se com os leitores, aos quais aqui e ali apenas entremostrava uma idéia fugidia, e logo desaparecia no próprio halo de luz que a envolvia (VIANA FILHO, 1949, p.07).

Nesta perspectiva, o enigma deixado por Afrânio Peixoto no telegrama pelo qual justificava sua ausência no Congresso Luso-Brasileiro de História - a que se refere Lúcia Paschoal Guimarães , pode ser enquadrado neste roteiro mais amplo de exacerbação dos enigmas e ironias presentes nas últimas publicações do autor. Mas, como demonstrar essa hipótese? Através da leitura atenciosa, quase microscópica das páginas de História do Brasil. Falando sobre a passagem da monarquia à república, o autor atacou:

o que existe aqui, sob o nome de democracia, é a apenas uma oligarquia políticomilitar, constituída por políticos profissionais e militares que desdenham sua profissão, para a qual os nomes "monarquia ou "república" são vestidos exteriores, desajeitados e sem medida (PEIXOTO, 1940, p.190).

Talvez, um fragmento escrito na última página do livro nos ajude a compreender a esfinge de forma ainda mais clara. Ao realizar um balanço político e econômico sobre a situação histórica do Brasil nos anos trinta, Afrânio Peixoto expressou:

Falta-nos educação popular; falta-nos estadistas, que só podem trabalhar nelas apoiados [...] Entre as imposições do patriotismo, a primeira, está a lealdade, o 
dever de não esconder a verdade, para corrigir e acertar. Não bastam hinos, proclamações, veemências, que, exatamente, denunciam um complexo de inferioridade. Querer bem prova-se; patriotismo é acção. Deus nos acuda, se ainda é brasileiro, como tanto se diz (PEIXOTO, 1940, p.195).

Seria uma forma de sorrir, por meio da literatura, do ato que o impediu de participar das comemorações. O Congresso, com todas as luzes do nacionalismo autoritário, que caracterizava a ditadura de Salazar e de Vargas estaria sendo ironizado. As ritualizações da história de que nos fala Fernando Catroga (CATROGA,1998), tão marcadas por hinos, cultos aos símbolos e outras representações nacionais, temas exaustivamente explorados durante o Congresso do Mundo Português, conforme destacou Lúcia Paschoal Guimarães, foram diretamente criticadas por Afrânio.

A crítica ao patriotismo estéril não se limitaria ao Brasil, visto que a História do Brasil é a História da América Portuguesa. O autor deixara claro na epígrafe do romancista conservador Roberth Southey "Suceda o que suceder o Brasil será sempre uma herança de Portugal”. A dissidência luso-brasileira no discurso histórico de Afrânio Peixoto, operaria, então como uma imagem invertida: um livro sobre a história do Brasil criticando o patriotismo autoritário conduzido por Vargas publicado em Portugal, país ao qual o autor atribui toda nossa herança, inclusive, naquela conjuntura, a patriótica autoritária.

Um último registro. O patriotismo dissidente de Afrânio não passou despercebido também do público leitor brasileiro. Em 1942, diretores eleitos do Centro Acadêmico XI de Agosto da Faculdade de Direito do Largo de São Francisco, fez chegar à ABL pesadíssimas críticas ao livro História do Brasil. A nota, publicada em um jornal da capital paulista, não passou despercebida de um leitor de Afrânio que a recortou e inseriu no interior do livro que o autor desse artigo, por acaso, localizou em um sebo da cidade. O conteúdo trazia a seguinte mensagem:

\section{UM LIVRO INCONVENIENTE}

Rio, 16 (Estado - Via Vasp) - O embaixador José Carlos de Macedo Soares, presidente da Academia Brasileira de Letras, recebeu o seguinte telegrama:

"A Comissão Organizadora do futuro Departamento de Estudos Brasileiros e Panamericano do Centro Acadêmico "XI de Agosto" da Faculdade de Direito de São Paulo, vem protestar veementemente junto a v. exa. contra a monstruosa deturpação histórica contida nas afirmações do acadêmico Afrânio Peixoto, quando referindo-se à epopéia bandeirante ousou detratar aqueles que foram os construtores da nacionalidade.

Solicita, outrossim, a v. exa., providenciar a apreensão do livro "Noções de História do Brasil”, editado pela livraria Lelo, de Lisboa o qual contem infamantes assertivas do aludido acadêmico, a fim de que a formação cultural das futuras gerações não se inspire em obras impatrióticas e nocivas". - Oscar Augusto de Barros Bressane presidente eleito do Centro Acadêmico "XI de Agosto", da Faculdade de Direito de São Paulo; Luiz Azevedo Soares, orador eleito; Rivaldo de 
Assiz Cintra, Gilberto Quintanilha Riveiro, Fernando Melo Bueno, Jaime Bacari, Nestor da Rocha Bressane Filho.

Cabe ressaltar que a edição do livro de Afrânio somente foi publicada em $1944^{3}$ pela Companhia Editora Nacional como volume da coleção Biblioteca do Espírito Moderno ${ }^{4}$. A nota dos estudantes da Faculdade de Direito indica que antes mesmo de ser publicada no Brasil, o ensaio de Peixoto foi rejeitado por circuitos da cultura escrita situados às margens do poder, até certo ponto, em elevado grau de conflito contra o Estado Novo ${ }^{5}$. É muito provável que a detração à epopeia dos construtores da nacionalidade às quais se referem os representantes do Centro Acadêmico XI de Agosto encontre-se na definição de Bandeirantes empregada por Afrânio Peixoto inspirada em Capistrano de Abreu: "bandeirantes eram partidos de homens empregados para prender e escravizar o gentio indigente." (PEIXOTO, 1940, p.91). Ou tenham sido motivados pelos adjetivos empregados para qualificar a ação de determinados bandeirantes e paulistas, de que é exemplo Raposo Tavares:

Antônio Raposo Tavares parte, em 1629, com mil paulistas e dois mil índios, entram na direção do Paraguai e caem nas missões de Santo Antonio, exigindo a entrega de um prisioneiro índio que fugira e aí se asilara. O padre jesuíta defende o índio e recusa-se a entregá-lo. A carnificina e o incêndio foram a conseqüência (PEIXOTO, 1940, p.123).

Certamente, outra passagem, que provavelmente incomodou os leitores da academia do Largo de São Francisco, foi a qual Peixoto mencionou a aprovação da violência praticada contra os indígenas:

As entradas despovoadoras, captando o índio, deixavam o processo colonizadores, dos Jesuítas, de José Bonifácio, do General Rondon, seria preferível: mas a violência dos bandeirantes tem justificações de Varnhagen, de Von Ihering, de todos os coloniais europeus, que são amáveis com os povos bárbaros. Aliás, nem sempre eles os selvagens, têm a docilidade resignada. O mundo é dos capazes: é a lei de ferro da natureza e da civilização. O mesmo santo e doce Anchieta chegava à exasperação, para catequizar o índio: "para este gênero de gente não há melhor pregação do que espada e vara de ferros.(Cartas,p.186)" (PEIXOTO, 1940, p.124).

Neste caso, a natureza impatriótica da obra de Afrânio teria derivado do sentimento de paulistanidade e da centralidade que o papel desempenhado pelos bandeirantes ocupa na produção histórica sobre a formação do território nacional ${ }^{6}$. A versão permaneceu na edição brasileira. Já os excertos, abertamente críticos em relação ao patriotismo adorador de hinos e símbolos e pouco críticos em relação à realidade autoritária da república, estes foram suprimidos: teria sido esta a précondição para a publicação sair no Brasil? Ou as tensões geradas quatro anos antes já teriam sido arrefecidas pela força do 'Queremismo' que marcou o ano de 1944? 


\section{Referências Bibliográficas}

BESSA, Carlos. Homenagem da Academia Portuguesa da História ao Instituto Histórico e Geográfico Brasileiro no seu sesquicentenário. Revista do IHGB, 150(364):361-527, julho setembro, 1989.

CATROGA, Fernando. Ritualizações da história. In: CATROGA, Fernando, TORGAL, Luiz Reis e MENDES. História da História em Portugal. - da historiografia à memória histórica. Lisboa: Temas e Debates, 1998.

CHARTIER, Roger. Critica textual e história cultural: o texto e a voz, séculos XVI-XVII. Leitura, Teoria e Prática, no 30, Campinas: Mercado Aberto, 1997.

DANTAS, Júlio. In: COMISSÃO EXECUTIVA DOS CENTENÁRIOS. Congresso do Mundo Português. XIX volume. Programas, discursos e mensagens. Lisboa,1940.

DIAS, Maria Odila S. O fardo do homem branco: Southey, historiador do Brasil. São Paulo: Companhia Editora Nacional 1974.

GENETTE, Gérard. Umbrales. México: Siglo Veitiuno Editores, 2001.

GUIMARÃES, Lúcia Maria Paschoal. À sombra das chancelarias:a preparação do Congresso LusoBrasileiro de História (Lisboa, 1940). Revista do IHGB, 168(437):49-66,out/dez.2007.

GUIMARÃES, Lúcia Maria Paschoal. Relações culturais luso-brasileiras: encontro e desencontros. In: XII ENCONTRO REGIONAL DE HISTÓRIA - ANPUH. Anais do XII Encontro Regional de História: Usos do Passado - ANPUH-RJ, 2006.

LEITE, Serafim. Palavras do padre Serafim Leite. Lisboa (Torre do tombo), 22 de janeiro de 1947. Apud. RIBEIRO, Leonidio.

LOPES, Eliane Marta Teixeira. Júlio Afrânio Peixoto. Dicionário de Educadores do Brasil. Rio de Janeiro: UFRJ/MEC: INEP, 2008.

LUCA, Tânia de. A Revista do Brasil: um diagnóstico para a (N)ação. São Paulo: Ed.Unesp, 1999.

MOTA, Joaquim Antônio César; LOPES, Eliane M. Teixeira; CÓSER, Silvana M.L. Júlio Afrânio Peixoto (1876-1947): ensaio biográfico. In: HERSCHMANN; PEREIRA, Carlos Alberto Messeler. A invenção do Brasil moderno: medicina, educação e engenharia nos anos 20-30. Rio de Janeiro: Rocco, 1994.

PEIXOTO, Afrânio. História do Brasil. Lisboa: Lello \& Irmãos, 1940.

PEIXOTO, Afrânio. Minha terra e minha gente. $3^{\text {a }}$ d. Rio de Janeiro: Francisco Alves; LisboaParis: Aillaud e Bertrand, 1929.

PINSKY, Jaime. Nação e ensino de história no Brasil. In: O ensino de história e a criação do fato. $10^{\mathrm{a}}$. Ed. São Paulo: Contexto, 2002.

RIBEIRO, Leonidio. Afrânio Peixoto. Rio de Janeiro: Edições Conde, 1950.

SOUTHEY, Robert. História do Brasil. $3^{\mathrm{a}}$ ed. bras. São Paulo: Obelisco, 1965. 
TORGAL, Luís reis. O Estado Novo, Salazarismo, Fascismo e Europa. In: TENGARRINHA, José (org.). História de Portugal. $2^{\mathrm{a}}$ ed. Bauru, SP: EDUSC; São Paulo, SP: UNESP; Portugal, PT: Instituto Camões, 2001. pp. 391. 415.

VELLOSO, Mônica Pimenta. Em busca da identidade nacional: diferentes expressões do moderno e da brasilidade. In: MAGALDI, Ana Maria; ALVES, Claudia; GONDRA, José G (orgs.). Educação no Brasil: história, cultura e política. Bragança Paulista, SP: Edusf, 2003.

VENÂNCIO FILHO, Alberto. Culto a Imortalidade - Afrânio Peixoto. In: Revista Brasileira, Fase VIII, out-nov-dez, 2007, ano XIII, n53.

VIANA FILHO. Luís. Afrânio Peixoto (Romance). Rio de Janeiro: Agir, 1963.

\section{NOTAS}

${ }^{1}$ Refiro-me as considerações de FOUCAULT, Michel. A reelaboração política da idéia de nação na revolução. In: A Defesa da Sociedade. São Paulo: Martins Fontes, 2002. pp.257-284.

${ }^{2}$ Esta carta, como também as seguintes, foi inserida na condição de posfácio na $2^{\mathrm{a}}$ edição de Minha terra, minha gente, publicado pela Editora Francisco Alves em 1919.

${ }^{3}$ Cf: PEIXOTO, Afrânio. História do Brasil. 2a ed. São Paulo: Companhia Editora Nacional, 1944)

${ }^{4}$ Sobre a publicação de coleções como estratégia editorial no campo tem sido estudado por TOLEDO, Maria Rita de Almeida. Coleção Atualidades Pedagógicas: do projeto político ao projeto editorial (1931-1981). (Tese, PUCSP) São Paulo, 2001. Registre-se ainda a tese de doutorado em andamento de. FONSECA, Silvia Asam da. A biblioteca do espírito moderno e a formação do professorado secundário. Tese de doutorado em andamento no Programa de Estudos Pós-graduados em Educação, História, Política e Sociedade da PUC-SP.

${ }^{5}$ Os conflitos entre os acadêmicos da Faculdade de Direito de São Paulo e o governo Vargas estão registrados em: SCHUBSKY, Cássio (coord.). A heróica pancada: Centro Acadêmico XI de Agosto: 100 anos de luta. São Paulo: Memojus, 2003.

${ }^{6}$ Em relação a construção histórica do bandeirante ver: ABUD, Kátia Maria. Sangue intimorato e as nobilíssimas tradições: a contribuição de um símbolo paulista: o bandeirante. São Paulo, 1987. (FFLCH-USP Tese de Doutorado); FERREIRA, Antonio Celso. A epopéia bandeirante: letrados, instituições, invenção histórica (1870-1980). São Paulo: Edunesp, 2002.

Artigo recebido em 10/2009. Aprovado em 12/2009. 